\title{
The Current Role of Chemical Engineering in Solving Environmental Problems
}

\author{
Antoni Sánchez* \\ Department of Chemical, Biological and Environmental Engineering, Autonomous University of Barcelona, Barcelona, Spain
}

Keywords: chemical engineering, environmental engineering, waste treatment, life cycle assessment, circular economy, wastewater treatment, circular economy (CE)

Chemical Engineering (CE) has demonstrated to be a powerful tool to have comprehensive solutions to a wide range of environmental problems. Classical disciplines of CE have been extensively applied to typical and emerging environmental technologies such as wastewater treatment, anaerobic digestion, biofiltration, etc. Among them, it is important to highlight these CE classical topics: chemical reactors design, kinetics, simulation, control, modeling and especially, heat and mass balances.

Through these CE fundamentals, a lot of environmental processes have been described and designed. However, environmental science and technology is evolving so fast that some processes still need a CE approach.

In my opinion, waste biological treatment is the topic where more CE approaches are needed. From composting, which is a robust and well implemented technology, and where most of the decisions are based on "rules of thumb" criteria, to solid-sate fermentation, the new paradigm of circular economy to convert wastes into new bioproducts, there are only first approaches to use the CE paradigms. Some studies on composting modeling, or even the use of Computational Fluid Dynamics (CFD) can be found in literature, but it is not a general rule. I really wonder if solid-state experiments can be realistic when using some grams of substrate under controlled and sterilized lab conditions (El-Bakry et al., 2015).

Anyway, some recent studies are being presented when scaling-up solid waste treatments.

Edited and reviewed by: Fengai You, Cornell University, United States

*Correspondence: Antoni Sánchez antoni.sanchez@uab.cat

Specialty section:

This article was submitted to Environmental Chemical Engineering, a section of the journal

Frontiers in Chemical Engineering

Received: 16 August 2019 Accepted: 11 October 2019 Published: 25 October 2019

Citation:

Sánchez A (2019) The Current Role of

Chemical Engineering in Solving Environmental Problems.

Front. Chem. Eng. 1:1

doi: 10.3389/fceng.2019.00001 Microbiology seemed to be a drawback for these studies, but recent papers have adapted modern techniques to complex solid matrices, such as those found in composting and solidstate fermentation. The future for this important part of environmental studies is clear and many rigorous studies are necessary to consolidate it.

Water and wastewater treatment are one or two steps forward. Complex models are being presented and analyzed, and some of them implemented at full-scale. Today, researchers are focusing these emerging studies not on the treatment of these wastewaters, but on the recovery of their compounds. A paradigmatic research trend is the recovery of phosphorous, which has important and relevant advances. In this same trend, the transformation of wastewater into bioplastics is another top research line, although the behavior of these biodegradable plastics needs further research.

Considering the three main pollutant sources, gaseous emissions have been, without any doubt, the topic of many studies related to the use of $\mathrm{CE}$ tools to provide reliable and consistent information about their abatement and transformation. From chemical processes (scrubbers) to more complex biological processes (biofiltration and biotrickling filters, especially), researchers have an extensive collection of realistic studies to treat and model this equipment. Microbiology has been easily incorporated to these biological treatments, giving consistency to the models developed.

Another important emerging trend is the use of nanotechnology to solve environmental problems. This multidisciplinary approach has a lot of problems to be published: is this a 
nanotechnology or and environmental paper? The answer to this question is: it is both, but it seems that some journals are not prepared for that. It is the responsibility of researchers to change this mentality, and important efforts are being made. All of these are welcome. CE is, by definition, a multidisciplinary approach to real problems (Alonso et al., 2017; Abo Markeb et al., 2019).

After these brief considerations about the state-of-the-art of the three main issues considered in environmental problems: liquid, gas and solid, two main topics appear as major questions in deciding technologies for environmental treatments and involving all the stakeholders (some of them are not familiar with the research field): Life Cycle Assessment (LCA) and Circular Economy. Additionally, issues such as circular economy and food-energy-water-waste nexus could be systematically analyzed using LCA tools (both attributional and consequential).

LCA is a developed version of the typical CE mass and heat balances of a technology or product (or even more than this, "from cradle to grave") to define the environmental impacts that are often expressed as some pollution categories. Being a powerful tool, and recommended for making decisions, scientific papers such consider that this analysis, to be consistent and reliable, need the use of realistic data (Colón et al., 2012). This is not what happens sometimes, and it is the role of scientists to enlarge the databases of environmental processes to have concluding results. An enormous field of research is awaiting (Komilis and Sánchez, 2017).

The second and most transversal is the relatively recent term of "circular economy." It is somewhat surprising that practically everybody understands what circular economy is about, but often no economy is found in the studies focused on this topic (Sánchez et al., 2015; Abu Yazid et al., 2017). This term (recent but previously known with other names) is related to the need of closing cycles, especially when dealing with energy and materials. Being a fashionable term, one wonders if the composting and anaerobic digestion studies performed 30 years ago do not deserve to be considered circular economy (Ruggieri et al., 2009; Abraham et al., 2014). Anyway, it is circular economy, then: why most of the published papers on this topic do not have a simple cost analysis? There is a need to fulfill this gap, as big as the controversial use of this term. This point does

\section{REFERENCES}

Abo Markeb, A., Llimós-Turet, J., Ferrer, I., Blánquez, P., Alonso, A., Sánchez, A., et al. (2019). The use of magnetic iron oxide based nanoparticles to improve microalgae harvesting in real wastewater. Water Res. 159, 490-500. doi: 10.1016/j.watres.2019.05.023

Abraham, J., Gea, T., and Sánchez, A. (2014). Substitution of chemical dehairing by proteases from solid-state fermentation of hair wastes. J. Clean. Producti. 7, 191-198. doi: 10.1016/j.jclepro.2014.03.035

Abu Yazid, N., Barrena, B., Komilis, D., and Sánchez, A. (2017). Solid-state fermentation as a novel paradigm for organic waste valorisation: a review. Sustainability 9:224. doi: 10.3390/su9020224

Alonso, A., Moral-Vico, J., Markeb, A. A., Busquets-Fité, M., Komilis, D., Puntes, V., et al. (2017). Critical review of existing nanomaterial adsorbents to capture carbon dioxide and methane. Sci. Total Environ. 595, 51-62. doi: 10.1016/j.scitotenv.2017.03.229 not need to be confirmed, as any CE course or project include an economic evaluation. Economic analyses are not always well received by scientific journals. If they are consistent and rigorous, they are an essential part of any environmental solution. How many times researchers read a good technical solution, but they think that it cannot implemented as it does not make sense in economic terms?

In this framework, it is relatively easy to deduce the general areas where CE principles can be used for the complete solution of environmental problems:

(1) Apply CE consolidated paradigms: among them, mass and heat balances should be the first ones.

(2) Multidisciplinary: most environmental problems do not have a unique solution. Biological treatments do no discard the help of other physico-chemical treatments.

(3) Do not think on disposal, think on recovery: a typical example of this problem is the use of adsorption to "remove" pollutants from water. And then, what? You have not removed anything, it is only a pollutant transport.

(4) When possible, try to do an approximation using LCA principles. If built with realistic data, it will give you clues about if your proposal is as good as you think.

(5) When possible (and when not), estimate the economic viability of your proposal.

In summary, $\mathrm{CE}$ tools are a powerful tool to explain, interpret and model environmental problems, from the mere technological point of view to more complex LCA and circular economy analyses.

\section{AUTHOR CONTRIBUTIONS}

AS was the specialty chief editor of environmental chemical engineering in frontiers in chemical engineering.

\section{FUNDING}

The author thanks the Spanish Ministerio de Economía $y$ Competitividad for its financial support (Project CTM2015-69513-R).

Colón, J., Cadena, E., Pognani, M., Barrena, R., Sánchez, A., Font, X., et al. (2012). Determination of the energy and environmental burdens associated to the biological treatment of source-separated Municipal Solid Wastes. Energy Environ. Sci. 5, 5731-5741. doi: 10.1039/C2EE01085B

El-Bakry, M., Abraham, J., Cerda, A., Barrena, R., Ponsá, S., Gea, T., et al. (2015). From wastes to high value added products: novel aspects of SSF in the production of enzymes. Crit. Rev. Environ. Sci. Technol. 45, 1999-2042. doi: 10.1080/10643389.2015.1010423

Komilis, D., and Sánchez, A. (2017). Life cycle assessment in solid waste management: facts and artefacts. Waste Manage. 61, 1-2. doi: 10.1016/j.wasman.2017.03.016

Ruggieri, L., Cadena, E., Martínez-Blanco, J., Gasol, C. M., Rieradevall, J., Gabarrell, X., et al. (2009). Recovery of organic wastes in the Spanish wine industry. Technical, economic and environmental analyses of the composting process. J. Clean. Product. 17, 830-838. doi: 10.1016/j.jclepro.2008. 12.005 
Sánchez, A., Artola, A., Gea, T., Barrena, R., and Font, X. (2015). A new paradigm for waste management of organic materials. Waste Manage. 42, 1-2. doi: 10.1016/j.wasman.2015.05.002

Conflict of Interest: The author declares that the research was conducted in the absence of any commercial or financial relationships that could be construed as a potential conflict of interest.
Copyright (c) 2019 Sánchez. This is an open-access article distributed under the terms of the Creative Commons Attribution License (CC BY). The use, distribution or reproduction in other forums is permitted, provided the original author(s) and the copyright owner(s) are credited and that the original publication in this journal is cited, in accordance with accepted academic practice. No use, distribution or reproduction is permitted which does not comply with these terms. 